\title{
ANOREXIA MENTAL COMO RESISTÊNCIA À ONIPOTÊNCIA MATERNA
}

Denise da Silva Barbosa

\author{
Especialista em \\ Saúde Mental e \\ Clínica. Mestre \\ em Estudos \\ Psicanalíticos pela \\ UFMG. Psicóloga \\ clínica da Polícia \\ Militar de Minas \\ Gerais.
}

RESUMO: Aborda-se a complexa relação do sujeito com o desejo da mãe no âmbito do fenômeno da anorexia mental. Destaca-se a relação que se estabelece entre a satisfação pulsional obtida pela atividade alimentar e o funcionamento mental na produção de sintomas concernentes ao transtorno alimentar. Evidencia-se o aspecto fundamental da singularidade própria da interferência do componente mãe/filha sobre o aparecimento dos sintomas anoréxicos, ou seja, a anorexia mental como resistência à onipotência materna.

Palavras-chave: anorexia mental, desejo, onipotência materna, objeto nada.

ABSTRACT: Mental anorexia as resistance to maternal omnipotence. The text discusses the complex relationship of the subject with the mother's desire in the scope of the phenomenon of mental anorexia. It highlights the established relationship between the pulsional satisfaction from the feeding activity and the mental functioning in the production of symptoms related to the eating disorder. It focuses on the fundamental aspect of the singularity characteristic of the interference of the component mother/daughter on the appearance of the anorexic symptoms, that is, the mental anorexia as a resistant element to the maternal omnipotence.

Keywords: mental anorexia, desire, maternal omnipotence, object nothing.

\section{INTRODUÇÃO}

Tornou-se clássico para o enfoque psicanalítico da anorexia mental o exame da interferência da tríade mãe/criança/objeto oral na produção de sintomas concernentes ao transtorno alimentar. Desde seu início, a obra de Sigmund Freud é exemplar quanto ao número de referências que explicitam essa correlação entre a atividade alimentar e o funcionamento mental. 
Dentre essas passagens, destaco aquelas que evidenciam as implicações da relação mãe/filho e o contexto da satisfação oral. Freud expõe que, no momento em que inicia o ato de sugar, a criança obtém suas primeiras experiências de prazer associadas à satisfação da necessidade de nutrição: “[...] o estímulo do morno fluxo do leite é a causa da sensação de prazer” e, assim, “de início, a atividade sexual se liga a funções que atendem à finalidade de autopreservação e não se torna independente delas senão mais tarde" (FREUD, 1905, p.186). Essa separação é inevitável, uma vez que surgem os dentes e a mastigação.

Assim, a criança não se serve de um objeto externo para sugar, mas prefere uma parte de sua própria pele, porque isso lhe é mais cômodo, porque a torna independente do mundo externo. Não apenas pelo fato de que ela ainda não consegue dominá-lo, mas também porque, ao sugar o próprio corpo, ela se proporciona uma segunda zona erógena. A inferioridade dessa segunda região a levará, mais tarde, a buscar em outra pessoa a parte correspondente: os lábios. E subjacente a isso, continua Freud, seria como se dissesse: “[...] pena eu não poder beijar a mim mesma" (idem).

Percebe-se que Freud associa uma primeira satisfação, a da necessidade de nutrição ligada à preservação da vida, a uma segunda, concernente ao estímulo da zona labial, que, mais tarde, se destaca da primeira. As duas satisfações então se separam. Isso fica visível quando o bebê suga o próprio dedo, por exemplo. Vale salientar que, por não poder beijar a si mesmo, busca, mais tarde, os lábios de outra pessoa, o que põe em evidência a atividade própria do movimento pulsional.

A zona dos lábios ganha, assim, uma especial importância, uma significação erógena para o sujeito. A partir daí, ao estudar o ritmo da sucção, Freud presume que, nas crianças em que o sugar se acentua, existe uma intensificação constitucional da importância erógena dos lábios. Se essa importância persiste, elas terão fortes tendências para o alcoolismo e o tabagismo. Caso sobrevenha o recalcamento, sentirão nojo da comida e produzirão vômitos histéricos. É em função dessa dupla finalidade da zona labial que o recalcamento se estende à pulsão de nutrição. Freud afirma que várias de suas pacientes com distúrbios alimentares foram, na infância, firmes adeptas do sugar.

Constata-se nessa observação conceitual sobre a oralidade que o autor postula influência entre a atividade de satisfação e a sucção na própria produção dos transtornos mentais relacionados à alimentação. É nesse sentido que, nas descrições do método primário de funcionamento do aparelho psíquico, em Interpretação de sonhos (FREUD, 1900), depara-se com o exemplo do bebê que, na tentativa de reconstituir a situação da primeira satisfação, cria um caminho mais curto e se realiza por meio da alucinação. No entanto, tendo em vista que a alucinação não basta para satisfazer sua necessidade de se nutrir, a criança busca ajuda de um Outro que lhe forneça o alimento. Nesse mesmo texto, Freud mostra que 
a atividade de pensar nada mais é que um substituto da alucinação. Ou seja, a ausência da satisfação esperada leva o aparelho psíquico a decidir-se por um caminho diverso do da alucinação.

Mais adiante, em 1925, em seu texto A negativa, acrescenta que "[...] o pensar tem a capacidade de trazer diante da mente, mais uma vez, algo outrora percebido, reproduzindo-o como representação sem que o objeto externo ainda tenha de estar lá” (FREUD, 1925, p.298). Portanto, na verdade, o que se busca na realidade externa não é encontrar um objeto que corresponda ao representado, mas, sim, reencontrar o objeto e convencer-se de que ele está lá. No entanto, a precondição disso é que o objeto em questão, que, outrora, trouxera satisfação real, tenha sido perdido.

Para Lacan, um objeto pode exercer influência em um sujeito bem antes de ser percebido como tal. O objeto é real, e a relação, direta. Será em função de uma periodicidade em que podem aparecer furos e carências que vai se estabelecer certo modo de relação do sujeito que, até então, não necessita em absoluto que haja para ele distinção entre um eu e um não-eu (FREUD, 1925). Sabe-se que na relação fundamental da criança com a mãe, a existência da mãe não supõe, no entanto, que haja um eu e um não-eu. Não há para a criança, nesse momento, diferenciação entre ela e a mãe.

Muito cedo, a oposição eu versus não-eu impõe-se ao indivíduo. Porém, bem no início da vida psíquica, há uma situação em que o eu se encontra totalmente tomado por pulsões e, em parte, é capaz de satisfazê-las em si mesmo. A essa possibilidade de satisfação, Freud emprega o adjetivo autoerótica (FREUD, 1915). No momento inicial da concepção do aparato psíquico, ou seja, nos primeiros textos freudianos, fica claro que no plano das representações algo permanece não assimilável, algo fica excluído dessa organização psíquica. O aparato psíquico ainda não pode ser considerado um aparato propriamente dito. Sendo assim, isto que fica excluído da futura organização psíquica, não é parte integrante dela. Mas é em torno desse algo que a organização psíquica se faz. Neste estado originário do psiquismo ainda não há distinção entre o eu e o mundo exterior, ou oposição entre o prazer-desprazer, pois o eu satisfaz as pulsões em si mesmo, autoeroticamente. Nesse momento, o mundo exterior é indiferente para o sujeito.

Nessa relação primitiva, o objeto não tem instância, nem entra em função, a não ser pela ausência, pois só será evocado a partir de sua falta. É importante salientar que aqui está o começo da ordem simbólica para o sujeito. Um sintoma como o da anorexia mental está relacionado necessariamente com esse caminho de tornar simbólico o objeto.

A mãe, então, não surge como objeto desde o início na relação com a criança. Ela aparece como agente dos primeiros jogos de domínio sobre um objeto perfeitamente indiferente em si mesmo e sem nenhuma espécie de valor biológico. 
A criança articula de modo extremamente precoce o par presença-ausência. É o que se observa na brincadeira do Fort-da: ${ }^{1}$ a criança faz uso da vocalização 'O-O-Oo’ e ‘da'. Ou seja, utiliza um mesmo registro para evocar o objeto na sua ausência ou para rejeitá-lo quando presente. Nesse momento a criança se situa entre o agente, que é a mãe, e o emparelhamento presença-ausência. Mas isso ainda é insuficiente para constituí-la. É preciso, em seguida, uma série agrupada como tal, como condição de uma ordem simbólica. A partir daí, o agente simbólico, ou seja, a mãe, pode não responder.

O Fort-da nos mostra como o objeto real se torna simbólico: a mãe não responde. Ela não está lá para responder ao apelo. Dessa forma, não obedece ao apelo simbólico da criança. Ela não está reduzida ao significante que, até então, obedecia a um retorno periódico. Ao recusar-se a retornar ao mesmo lugar, ela para de jogar o jogo simbólico. Nesse sentido, o Fort-da é para a criança um esforço de domínio simbólico da mãe. É exatamente o fato de a mãe não responder que a torna uma potência (LACAN, 1956-1957).

Até então, no jogo do Fort-da, a mãe é simbólica e detentora dos objetos reais. A partir do momento que ela não responde, há uma inversão: ela torna-se real, como resistência ao simbólico, e o objeto torna-se simbólico. Há uma inversão entre o real e o simbólico. Assim, os objetos, que eram pura e simplesmente objetos de satisfação, tornam-se, por parte da potência materna, objetos de dom. Em suma, “[...] os objetos que a criança quer reter consigo não são mais tanto objetos de satisfação, e sim a marca do valor dessa potência que pode não responder, e que é a potência da mãe” (LACAN, 1956-1957, p.69).

O objeto vale, a partir daí, não por sua substância, ou suas qualidades. Ele toma valor como signo de amor da mãe, ou seja, objeto de dom. Ele é duas vezes possível de satisfação: num primeiro tempo, quando se toma a frustração em seu sentido simples, a criança pede o seio porque tem fome, porque é imprescindível nutrir-se. Assim, ela satisfaz uma precisão em que a satisfação é real, e substancial. Num segundo momento, o objeto simboliza a potência materna, torna-se signo de amor. O que está em questão aqui não é o objeto real, isto é, o da necessidade, mas o que entra em jogo nesse momento é o objeto na sua vertente de satisfação de amor. O objeto tem, a partir daí, insisto, duas ordens de propriedade satisfatória, ele é duas vezes objeto possível de satisfação. Desde já, adianto que esse ponto é de extrema importância para o entendimento do que Lacan afirma, quando aborda a relação da anoréxica com o objeto nada: ou seja, ele sustenta que, na anorexia, o que está em jogo não é o não comer, mas o

\footnotetext{
${ }^{1}$ Brincadeira do neto de Freud com um carretel, que ele atira de seu berço para fora de seu campo de visão, pronunciando um fonema, e puxa-o de volta enquanto pronuncia outro (FREUD, 1920, p.26).
} 
comer nada. Ela se satisfaz com o nada, que é o mais-além do objeto que tem a propriedade de estar ali simbolicamente.

Se o alimento oferecido pela mãe ganha seu valor como objeto real — objeto puramente nutricional — em detrimento de seu significado como simbólico, signo de amor, a criança pode responder com a produção de uma anorexia. Ela escolhe comer o nada do amor não ofertado, pois, assim, faz aparecerem os signos de amor, já que o essencial no amor é saber oferecer a própria falta. A mãe que oferta comida, cuidados e outras coisas, mas não dá ao sujeito o signo de sua falta, não deixa, desse modo, um lugar de valor para o Outro, não faz falta ao Outro. Sob a repetição significante do Fort-da, encontra-se a frustração. O que aparece no primeiro plano é a frustração da criança com relação à mãe da qual depende. O mais importante, porém, a se considerar no centro da relação mãe-criança é a frustração da mãe como mulher.

A relação mãe-criança é uma relação dialética. Por um lado, a mulher encontra na criança uma satisfação que atenua uma falta no imaginário. Por outro, a criança ameniza, mais ou menos bem, a necessidade de falo da mãe. Dessa forma, a criança, como real, assume para a mãe a função simbólica de sua necessidade imaginária, ou seja, a criança, como real, simboliza a imagem.

Sabe-se que, na relação mãe-criança, há sempre o falo, o significante que faz da mãe um ser em falta e, para o qual aponta o seu desejo. Sendo assim, quando se faz referência ou se elabora algo a respeito da relação mãe-criança, deve-se, primeiro, referir-se à relação mãe-falo.

Como saciar o desejo da mãe com respeito à falta fálica?

Essa é, para a criança, uma questão fundamental. A criança entra aí como solução possível da falta feminina. O ponto mais importante a se considerar é o de como a criança, na tentativa de solucionar a deficiência quanto ao desejo da mãe, descobre que não é suficiente para preenchê-la.

O falo tem estreita relação com a criança para a mulher - a mulher tem, dentre suas faltas de objetos essenciais, o falo. A criança satisfaz a necessidade de falo da mulher. Porém, importa salientar que a criança é um substituto insuficiente do falo.

A partir daí, apresenta-se a seguinte questão: o que acontece na medida que a imagem do falo para a mãe não é completamente reduzida à imagem da criança (LACAN, 1956-1957)?

Existe sempre, para a mãe, algo que permanece irredutível no que está em questão, pois nenhum objeto real que venha como substituto da falta na mãe consegue equacioná-la, isto é, não há como preencher a sua falta fálica da mãe. Para a criança, muito mais que se deparar com essa falta na mãe, é vêla afetada em sua potência. A mãe é insaciada, insatisfeita, procura algo para devorar. Segundo Lacan, a criança encontra-se diante dessa mãe com a bocarra 
escancarada: “Um grande crocodilo em cuja boca vocês estão - a mãe é isso. Não se sabe o que lhe pode dar na telha, de estalo fechar sua bocarra. O desejo da mãe é isso" (LACAN, 1969-1970, p.105).

A estratégia anoréxica diante do desejo da mãe é mostrar-se totalmente descarnada, não comestível, para não correr o risco de ser devorada por ela.

\section{OBJETO ORAL, DEMANDA E NECESSIDADE}

É imprescindível verificar o modo como, a partir de Freud, as formulações inovadoras de Jacques Lacan explicitam as diferentes modalidades da interferência do objeto oral na relação dual entre a mãe e o filho. Como já anunciado, na tríade mãe/filho/objeto oral, o que está em jogo é a forma como a criança toma posse desse objeto, é a atividade que assume uma função erotizada (LACAN, 1956-1957). É apenas por meio da demanda que a necessidade pode satisfazerse. Sendo assim, para satisfazê-la, é preciso subordiná-la ao significante. E, para tal, é necessária a função mediadora de alguém que traduza a necessidade em demanda. O grito de fome de um bebê, por exemplo, precisa da interpretação da mãe para ser transformado em demanda de comida. Muito mais importante que o objeto da necessidade é a mão que o oferece. O essencial da demanda não é o objeto da necessidade, mas o fato de que alguém responde dando algo (MILLER, 1997). Pois é exatamente aqui que se produz um desvio das necessidades. Por mais que as necessidades estejam subordinadas à demanda, elas retornam alienadas por ser do lugar do Outro que sua mensagem é emitida. A alienação das necessidades aparece como desejo (LACAN, 1958).

Como anunciado antes, na relação primordial com a mãe, o Outro é constituído pela demanda, que é demanda de uma presença ou de uma ausência. O Outro será, então, situado aquém das necessidades que ele pode suprir. A demanda constitui o Outro como tendo o privilégio de satisfazer as necessidades. A demanda constitui o Outro como tendo o poder de privar as necessidades da única coisa pela qual elas são satisfeitas. Esse privilégio do Outro desenha a forma radical do dom daquilo que ele não tem. É isso que se chama amor.

É dessa forma que a demanda anula a particularidade de tudo aquilo que pode ser concedido, transformando-o em prova de amor, e as próprias satisfações que a demanda obtém para a necessidade degradam-se em nada menos do que o esmagamento da demanda de amor. Isto é, “ao incondicionado da demanda, o desejo vem substituir a condição 'absoluta': condição que deslinda, com efeito, o que a prova de amor tem de rebelde à satisfação de uma necessidade" (LACAN, 1958, p.698).

Quando o objeto oferecido pela mãe adquire mais valor como objeto real, deixa assim escapar seu lugar de objeto simbólico, isto é, de objeto que faz signo de amor. A criança provavelmente dará como resposta a produção de uma estra- 
tégia anoréxica. Ela evidenciará a falta buscando o nada do amor. Dessa forma, ela põe em cena o objeto nada, ou seja, o signo de amor que falta ao objeto real oferecido. Tal estratégia do sujeito pode chegar ao extremo de se deixar morrer para cavar uma falta na mãe.

A partir da oferta, pode-se pensar em duas formas de demanda. A demanda pura e simples, aquela do objeto real, e a demanda de amor, a que demanda o objeto simbólico. Pode-se dizer, então, que a demanda de um objeto é sempre relativa àquilo que se dá, e que há um confronto entre o sujeito e o objeto que lhe faz falta, um embate condicionado ao outro que dá. A própria desarmonia entre sujeito e objeto demonstra que a demanda de um objeto visa sempre esse para-além do objeto. Sendo assim, pode-se dizer que a anoréxica busca o para-além do objeto, esse nada do objeto simbolizável que conserva em si um vazio.

Ao introduzir o amor, ou seja, o para-além do objeto real, introduz-se o nada. Sendo o falo isso que faz falta, há uma conexão entre o falo e o amor. Conexão essencial fundada pelo amor entre o objeto e o nada, pois o que é amado no objeto é exatamente aquilo que falta a ele: no amor, só se dá o que não se tem.

Há uma interessante passagem, em Lacan, que se encontra no Seminário 1, Os escritos técnicos de Freud, retirada do texto De Magistro de Santo Agostinho. Nesse diálogo, Santo Agostinho tem como interlocutor seu filho de apenas 16 anos: Adeodato. Santo Agostinho procura mostrar a Adeodato que todas as palavras são nomes e que é impossível manejar a linguagem referindo termo a termo o signo à coisa. Assim, propõe a Adeodato que diga o significado de cada palavra de um verso, que evoca a Troia desaparecida, da Eneida de Virgílio: "Se, de uma tal cidade, agrada aos deuses que não fique nada." Adeodato, ao tentar dar o sentido de cada palavra da frase, embaraça-se com a palavra nada e diz: "nada, evidentemente, é o que não existe”. Santo Agostinho, então, objeta que o que não existe não pode de maneira alguma ser algo.

“Será que não existe certa reação da alma quando, não vendo uma coisa, se dá conta, entretanto, ou acredita ter-se dado conta de que essa coisa não existe? Por que não dizer que tal é o objeto significado pela palavra nada, mais do que a coisa mesma, que não existe?" (SANTO AGOSTINHO, 354-430, p.293)

Portanto, o nada significa aqui ausência de algo que poderia estar lá, ou seja, o nada aqui presentifica uma ausência.

Curiosamente, vale ressaltar que no Seminário 1, Lacan desenvolve toda uma discussão sobre o significante e o significado no pensamento moderno sobre a linguagem e que, ao se referir ao diálogo de Santo Agostinho com seu filho, no ano de 389, diz que já estava tudo lá desenvolvido com uma lucidez sensacional (LACAN, 1953-1954). 
A ficção de amor tem consequências também sobre o que Lacan pode articular ou descobrir na conexão do amor e da pulsão. A tese geral de Lacan nesse seminário é a de que, quando o pulsional emerge numa cura analítica, pode-se produzir uma anorexia como tentativa de imprimir a função simbólica. Em outras palavras: "[...] a deficiência da relação simbólica que se precipita no pulsional” (MILLER, 1994, p.25).

Um bom exemplo da precipitação do pulsional no tratamento analítico é o caso que ficou conhecido como o caso do homem dos miolos frescos, um atendimento feito pelo analista Ernst Kris. ${ }^{2} \mathrm{O}$ paciente, um jovem cientista de trinta e poucos anos, ocupava com êxito uma posição acadêmica respeitada e não era capaz de avançar para um posto mais alto porque não se achava em condições de publicar nenhuma de suas extensas pesquisas. O impedimento acontecia pelo fato de se sentir impulsionado a roubar as ideias dos outros. Um dia, então, quando a publicação de um trabalho seu está na iminência de se materializar, ele chega à sessão e diz que acabara de se deparar com um livro publicado anos antes, no qual encontra as mesmas ideias do seu, o que o faz sentir-se plagiador a despeito de si mesmo. Era um trabalho com o qual estava familiarizado, já que o havia lido tempos atrás. Segundo E. Kris, o tom paradoxal de satisfação e de excitação do paciente o levou a inquirir detalhadamente sobre o texto que ele temia plagiar. Verifica-se, a partir de extensa avaliação, que a antiga publicação continha suporte valioso para sua tese, mas nenhuma alusão à tese propriamente dita. O paciente fez o autor dizer o que ele próprio queria dizer. Assim, o analista certifica-se de que seu paciente não é um plagiário, e o interpreta com a seguinte frase: “[...] apenas as ideias dos outros é que eram verdadeiramente interessantes, e somente as ideias poderiam ser tomadas; daí por diante, a forma de tomá-las tinha de ser arquitetada” (KRIS, 1951, p.129-30). E após um silêncio, que também é marcado por E. Kris, o paciente relata que todos os dias, após a sessão, sai em busca de seu prato predileto nos restaurantes da região: miolos frescos.

O paciente ocupa-se com miolos frescos, seu prato preferido, após cada sessão, para mostrar ao analista o equívoco de sua interpretação, que, ao invés de visar à verdade do sintoma, faz emergir a pulsão oral. Pode-se concluir, a partir daí, que o homem dos miolos frescos, ao contar ao analista sobre seu hábito de comer miolos após as sessões, apenas o faz para dizer a ele que não é possível abrir mão do nada.

Quando E. Kris constata e comunica ao paciente que não se trata de plágio, ou seja, que ele não rouba as ideias e que, na realidade, elas já eram dele, ele tenta desmontar a estratégia anoréxica que se arquiteta no roubar nada. Pois eleger um

\footnotetext{
${ }^{2}$ Ernst Kris (1900-1957), analista vienense contemporâneo de Lacan; importante representante da psicologia do ego, foi amplamente citado e metodicamente comentado por Lacan.
} 
tutor para suas ideias é a maneira que ele encontra para fazer aparecer o desejo por elas. Assim, o sujeito extrai algo de si, nesse caso, as suas ideias, para ser causado por elas no campo do Outro.

Reafirmo, então, como aponta Lacan, que a anorexia mental é uma estratégia do sujeito em relação ao desejo. O roubar nada do homem dos miolos frescos tem a mesma estrutura do comer nada daquelas que se recusam a comer. "A recusa delas, simbolicamente motivada, parece-me ter muita relação com a aversão do paciente por aquilo que ele cogita” (LACAN, 1958, p.607).

Percebe-se que é em torno de um vazio do objeto que gira toda a questão. A partir daí, pode-se afirmar que não se come somente para saciar a fome. Valoriza-se a ausência, o ponto vazio do objeto perdido. Pode-se dizer, então, que, na anorexia, não se trata propriamente de um distúrbio alimentar ou transtorno da alimentação, mas um modo de recuperar o vazio — impossível de comer — do objeto (RECALCATI, 2004).

\section{O OBJETO ENQUANTO TESTEMUNHO DO DOM ORIUNDO DA POTÊNCIA MATERNA}

Em $A$ direção do tratamento, o autor aborda os conceitos de necessidade, demanda e desejo na tentativa de esclarecer que, no plano da necessidade, já marcado pelo significante, um sujeito pode ser muito bem alimentado por uma mãe nutridora que lhe dá o seio diante da menor manifestação atribuída ao desprazer (LACAN, 1958). Observa-se, nesse contexto, a hipótese de manifestações de condutas anoréxicas, desde as primeiras mamadas de um bebê que recusa o peito com a intenção de criar uma hiância para, assim, testemunhar o amor de sua mãe (LACAN, 1957-1958).

É importante esclarecer que, quando, em A direção do tratamento, Lacan fala de testemunhar o amor da mãe, já havia proposto, no Seminário $A$ relação de objeto, que há um momento, na relação mãe-criança, em que a mãe se torna uma potência de que a criança depende para ter acesso aos objetos: “[...] objetos que eram até então, pura e simplesmente, objetos de satisfação, tornam-se, por parte dessa potência, objetos de dom” (LACAN, 1956-1957, p.69). Dito de outra forma: “[...] o objeto vale como testemunho do dom oriundo da potência materna". O que está em jogo, segundo o autor, é o modo como a criança apreende o objeto objeto que, a partir daí, se ordena de duas formas: satisfaz uma necessidade e marca o valor da potência materna.

Conforme já disse, a criança quer se nutrir. Então, ela pede uma satisfação real, precisa e substancial. Num segundo momento, o que ela aspira não é ao objeto real, trata-se do objeto de dom, objeto signo de amor, de quem se ocupa dela. Assim, a satisfação essencial não é a do objeto real, mas a satisfação do amor. Porque o amor pede, deseja nada de real, ele deseja um objeto como 
significante de amor. No fundo, essa exigência do signo de amor se conserva em sua intensidade por toda a vida.

Quando se fornece o substancial do objeto sem fornecer o signo de amor, é imperdoável! Pode-se dizer que a mais preciosa das satisfações é a simbólica que Lacan chama de amor, e que não é a satisfação de nenhum objeto real.

Então, a satisfação é simbólica. Mas isso não quer dizer que haveria recusa da satisfação real. Lacan, inclusive, faz alusão à evidente satisfação da criança, por exemplo, no seu adormecimento após se nutrir, mas não se pode recusar essa evidência de que, mesmo quando há satisfação real da necessidade, ela somente a quer ainda como substituta da satisfação simbólica. O que é rejeitado é a falta de amor. A satisfação do objeto real aparece como um substituto do amor. A falta de amor se compensa por uma satisfação real, é sempre assim.

Lacan elabora o conceito de frustração para dizer que o desejo no simbólico não é desejo de fazer reencontrar seu desejo. O desejo no simbólico é o amor. “O desejo visa à falta que introduz o significante" (LACAN, 1957, p.496). Sem dúvida, duplica-se o desejo na definição de amor: o desejo de fazer reencontrar seu desejo, e o amor é o desejo do desejo. No fundo, é isso que, explica o amor como o desejo de receber nada de real — o amor como desejo de nada. O objeto da frustração é menos o objeto real que o dom. A realidade do objeto desaparece com o amor, é sobre outro plano que aquele do puro e simples desejo natural. Enfim, a frustração não é de um objeto real, é a frustração de amor. Isso é o essencial da frustração (MILLER, 1994).

Na relação mãe-criança, é na medida que a criança chama a mãe e ela falta que o seio se torna mais significativo que tudo, ou, em outras palavras, o objeto da necessidade torna-se objeto de dom. Assim, a satisfação da necessidade passa a compensar a frustração do amor. Essa função econômica entre o objeto da necessidade e o objeto de dom é de equilíbrio e de compensação. A cada vez que há uma frustração de amor, esta é compensada pela satisfação da necessidade.

Ao tornar-se simbólico, o objeto encontra no caminho, necessariamente, o amor. O amor demonstra que o essencial é a maneira como se chega ao objeto. Assim, o mais importante na relação com o objeto é o nada. É preciso sempre dar lugar ao nada. Isso quer dizer que é necessário àqueles que encarnam o Outro para a criança saber dar a ela o nada, oferecer a falta. E o que faz obstáculo são as ideias preconcebidas que o Outro tem sobre as necessidades da criança. Se, no lugar de dar o nada, o Outro dá à criança "a papinha sufocante daquilo que ele tem, ou seja, confunde seus cuidados com o dom de seu amor" (LACAN, 1958, p. 634), a criança, então - diante desse Outro que no lugar de oferecer a falta, oferece comida, cuidados ou o que tem - , por outros meios, constrói o lugar do nada. E o exemplo que Lacan apresenta dessa construção é a anorexia mental. Para que a mãe não a empanturre com a papinha sufocante, é preciso, indica 
Lacan, que ela tenha um desejo fora da criança, que ela não seja tudo para ela. Pois, se à mãe falta a dimensão de um desejo fora da criança, esta fica condenada à alienação máxima de realizar a fantasia da mãe, acredita ser aquilo que falta à mãe, ficando, assim, totalmente presa no lugar de objeto da mãe. Pode-se dizer, então, que um sintoma como a anorexia aparece como um efeito de separação para que a criança possa soltar-se da posição passiva de objeto da mãe.

\section{ANOREXIA E A PREEMINÊNCIA DA IMAGEM DO CORPO PRÓPRIO}

Sabe-se que o estádio do espelho abarca o momento em que a criança reconhece sua imagem no espelho como própria, como imagem do corpo próprio. Até então, o bebê não tem uma percepção de si mesmo como unidade. O que tem são percepções internas provindas de diversas partes do corpo. Ele ainda não sabe de sua forma. Apenas reconhece as pessoas que cuidam dele. Ou seja, a imagem do outro é anterior à dele próprio.

Chega um momento em que algo diferente acontece. Depois de ser colocado inúmeras vezes diante do espelho, ele reconhece a imagem que tem a sua frente como sendo própria. Há um jogo de olhares. Ele olha para o espelho, fica fascinado pelo que vê, volta-se para aquele que o sustenta e solicita um assentimento. Reconhece o olhar no espelho dirigido a essa imagem que tem a sua frente e, assim, se instala o reconhecimento de sua imagem, isto é, o outro diz 'sim, você é isso'. Desse modo, o que está a sua frente se constitui como imagem do corpo próprio, mas trará aquilo que para o sujeito nomeará o seu ser, seu ser para o outro, pois é do outro que vem o 'você é isso'. Aqui o sujeito é falado; a voz do Outro que fala você é isso e opera como guia que comanda o sujeito. Ou seja, seu ideal do eu.

O ser humano capta a imagem do próprio corpo que passa a ser para ele um invólucro de domínio, uma forma que tem relação com a superfície do corpo, ou melhor, uma superfície enquanto refletida numa forma que se define pela superfície. Porém, necessita-se do movimento de troca com o outro para que o homem se apreenda como corpo. "Assim, o ideal do eu fica do lado do simbólico, do lado da intermediação do Outro” (LACAN, 1953-1954, p.157).

Nesse momento se produz a Verliebtheit, ${ }^{3}$ que se articula no registro da relação narcísica, da relação especular à relação com a imagem do outro e que dá ao sujeito a matriz em torno da qual se organiza para ele a sua incompletude vivida - o fato de que ele está em falta. Desta forma, a posição do sujeito na estruturação imaginária apenas é concebível se um guia se encontrar para além do imaginário, ao nível do plano simbólico, da troca legal que só pode se en-

\footnotetext{
${ }^{3}$ Substantivo derivado do verbo verlieben que se traduz por 'apaixonar'. No termo Verliebtheit, o verliebt é o particípio e o heit a terminação que indica substantivo feminino. Penso que a melhor tradução seria 'enamoramento'.
} 
carnar pela troca verbal entre os seres humanos. O guia que comanda o sujeito é o ideal do eu.

Na Verliebtheit introduz-se a função possível do ideal do eu que, introjetado, pode ser projetado sobre um objeto. À proporção que o ideal pode ser reprojetado, esse objeto de investimento ganha todo valor.

A cada vez que, no fenômeno do outro, algo aparece que permite de novo ao sujeito reprojetar, recompletar, nutrir em algum lugar a imagem do eu ideal, cada vez que se refaz de maneira analógica a assumpção jubilatória do estádio do espelho, cada vez que o sujeito é cativado por um de seus semelhantes, o desejo volta no sujeito, mas volta verbalizado. Em outras palavras, a cada vez que se produzem as identificações objetais do eu ideal, aparece o fenômeno verliebtheit (LACAN, 1953-1954). Antes que o desejo aprenda a se reconhecer, ele só é visto no outro, ou seja, o desejo aprende a se reconhecer pelo símbolo.

Então, o desejo em sua origem está alienado no outro. É especular, projetado no outro. A relação, nesse momento, é puramente imaginária. O desejo do sujeito só pode, nessa relação, se confirmar por meio de uma concorrência, de uma rivalidade absoluta com o outro quanto ao objeto para o qual tende, diz Lacan ao referir-se à cena em que Santo Agostinho vê e observa uma criança cheia de inveja, que ainda não falava e já olhava, pálida, de rosto colérico, para o “[...] irmãozinho de leite" (LACAN, 1953-1954).

\footnotetext{
"Quem não é testemunha do que afirmo? Diz-se até que as mães e as amas procuram esconjurar este defeito, não sei com que práticas supersticiosas. Mas, enfim, será inocente a criança quando não tolera junto de si, na mesma fonte fecunda do leite, o companheiro destituído de auxílio e só com esse alimento para sustentar a vida?" (SANTO AGOSTINHO, 397-400, p.45)
}

Se o outro preenche essa imagem de si, a imagem do eu, ele se torna objeto de investimento narcísico, ou seja, objeto da verliebtheit. Se, ao contrário, na mesma vertente o outro aparece como frustrando o sujeito do seu ideal e da sua própria imagem, engendra a tensão destrutiva máxima (LACAN, 1953-1954).

Há um contraste entre o que está ali projetado em sua frente no espelho, que lhe produz o júbilo, e aquele algo de incompleto que se manifesta em seus próprios gestos.

Vale destacar que a imagem do corpo do outro é anterior em relação ao próprio corpo. A imagem do corpo próprio não é captada num primeiro momento, o gozo do corpo está livre da concentração que se dará na captação da imagem do corpo próprio. Com a captação da imagem do corpo próprio, tem-se o gozo do corpo imaginário. Já o terceiro momento corresponderia ao jogo fálico, que interviria finalmente em cada um como uma anomalia. 
Assim, a constância da preeminência da imagem do corpo próprio nos seres humanos tem a ver com a suposição de uma falta, de um buraco, que a imagem do corpo viria tamponar (MILLER, 1995).

É sabido que quando o sujeito capta a totalidade de seu corpo próprio em sua reflexão especular, ele experimenta um momento de triunfo de caráter duvidoso, pois esse momento também introduz a depressão. Essa significação que se introduz a partir da imagem especular não é uma significação estável, é uma significação vacilante. Assim, “[...] o momento de seu triunfo é também o mediador de sua derrota" (LACAN, 1956-1957, p.190). Lacan argumenta que quando o bebê se encontra na presença da totalidade sob a forma do corpo materno, ele constata a não obediência dela. E, quando o estádio do espelho entra em jogo, a onipotência materna só é refletida, então, em posição depressiva, e faz surgir o sentimento de impotência da criança, uma vez que essa forma lhe foi dada pelo outro. É nesse momento que Lacan insere a anorexia mental como resistência à onipotência materna nessa relação de dependência.

A estratégia anoréxica põe em jogo a onipotência da mãe, faz-se uma inversão com relação ao domínio do Outro. Dessa forma, ela não fica à mercê do Outro, mas à mercê de si própria. Parece-me que é com a inversão de domínio que ela anula a decepção medular de toda ordem simbólica.

Saliento que a inversão não seria simplesmente a de domínio da mãe em relação à filha para domínio da filha em relação aos caprichos da mãe. A inversão de que se trata aqui seria em relação à filha e ela mesma, quando vai ocupar a posição caprichosa do Outro da qual ela se defendia. Na oscilação especular, ela vai ocupar as duas posições, como dirá Lacan, sem verdadeira saída dialética. A partir desse ponto de inversão, a dimensão do desejo poderá surgir do lado da mãe, e pode-se afirmar que é desse jogo que se trata na anorexia mental.

Recebido em 26/8/2008. Aprovado em 11/12/2008.

\section{REFERÊNCIAS}

FREUD, S. (1977) Edição standard brasileira das obras completas de Sigmund Freud. Rio de Janeiro: Imago. (1900-1901) “A interpretação dos sonhos". vs.IV e V, p.1-725. (1905) “Três ensaios sobre a teoria da sexualidade”. v.VII, p.123-250.

(1915) “As pulsões e suas vicissitudes”. v.XIV, p.129-162.

(1920) “Além do princípio do prazer”. v.XVIII, p.13-85.

(1925) “A negativa”. v.XIX , p.293-300.

KRIS, E. (1987) Psicologia do ego e interpretação na terapia psicanalítica. Falo, n. 1, Salvador, p. 125-30. 
LACAN, J. (1953-54/1986) O Seminário livro 1, Os escritos técnicos de Freud. Rio de Janeiro: Jorge Zahar. . (1956-57/1995) O Seminário livro 4, A relação de objeto. Rio de Janeiro: Jorge Zahar.

. (1957-58/1999) O Seminário livro 5, As formações do inconsciente.

Rio de Janeiro: Jorge Zahar.

(1958/1998) "A instância da letra no inconsciente ou a razão desde Freud”, in Escritos. Rio de Janeiro: Zahar.

. (1958/1998) “A direção do tratamento e os princípios de seu poder”, in Escritos. Rio de Janeiro: Jorge Zahar.

. (1969-70/1992) O Seminário livro 17, O avesso da psicanálise. Rio de Janeiro: Jorge Zahar.

MILLER, J-A. (1994) Donc. Paris: (Curso inédito).

(1995) La imagen del cuerpo en psicoanálisis. Cuadernos andaluces de psicoanális. n.16. Málaga: Grupo de Estudos Andaluz GEA de la Escuela Europea de Psicoanálisis del Campo freudiano, p.12-24.

Zahar. . (1997) Lacan elucidado - Palestras no Brasil. Rio de Janeiro: Jorge

RECALCATI, M. (2004) La ultima cena: anorexia y bulimia. Buenos Aires: Editora del Cifrado.

SANTO AGOSTINHO (1996) Os pensadores. Confissões. Livro 1. São Paulo: Nova Cultural. . (1984) Os pensadores. De magistro. São Paulo: Abril Cultural.

Denise da Silva Barbosa

denisesbarbosa@uol.com.br 